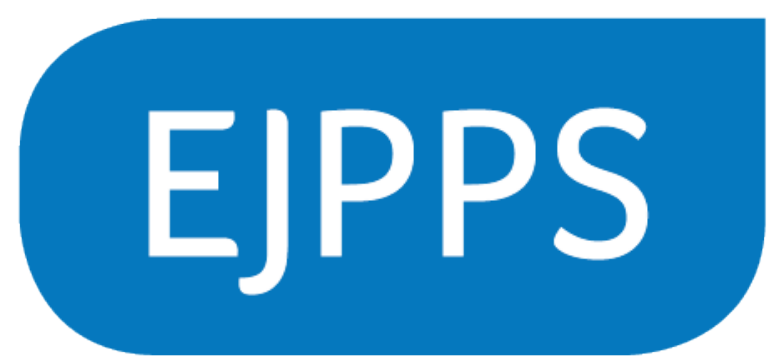

EUROPEAN JOURNAL OF

PARENTERAL AND

PHARMACEUTICAL SCIENCES

EJPPS - European Journal of Parenteral and Pharmaceutical Sciences Volume 25 Issue 4 https://www.ejpps.online/wetloads-a-phenomenon-or-by-design https://doi.org/10.37521/ejpps.25403

\title{
Wet loads - a phenomenon or by design?
}

\author{
Corresponding Author: Alan Heavey, Director, Consultant Sterilizing Engineer \\ PHSS Management Committee Member \\ Sterilization Solutions Ltd
}

Email: alan@sterilizationsolutions.co.uk 


\title{
Wet loads - a phenomenon or by design?
}

\author{
Alan Heavey, Director, Consultant Sterilizing Engineer/PHSS Management Committee Member \\ Sterilization Solutions Ltd
}

Having been involved in moist heat sterilization and autoclaves for over 40 years it fascinates me that there still exists in our industry confusion and misunderstanding in relation to wet loads.

I have therefore decided to write this short story to highlight the fact that, despite the occasional (or should we say frequent) denial within our industry of the existence of wet loads, they do actually occur in relation to porous/hardware loads autoclaved within the pharmaceutical and biotech industry. In fact, I would like to receive a pound for every time I have been asked the question, "Alan, when is wet, wet?"

This story is not to discuss whether loads should be wet or dry, but rather to discuss how to avoid the manifestation of a wet load in the first place by effective system design and good practice. And to save production time. Isn't that worth reading about?

So, where to start? I would suggest that like all good stories, we should start at the beginning.......

\section{Let's start with the Pure Steam Generator:}

It's a good idea to look at the 'whole system' in relation to wet loads, and by that I mean starting with the source of the steam, i.e. the Pure Steam Generator (PSG), moving through to the autoclave and finally the load items.

I think it is reasonable to suggest that the whole steam supply system should be designed to deliver steam to the autoclave in a reproducible manner and that the steam should be of a known and suitable quality to ensure efficacy of sterilization, whilst allowing for the delivery of a dry load on completion of an autoclave cycle.

For as long as I have been involved in moist heat sterilization, it has been recognized that the steam produced by the PSG should have known steam quality attributes, specifically in relation to its dryness, level of non-condensable gases and superheat. In relation to dryness, the current version of EN 285 suggests a dryness value not less than 0.95 ; however, from my personal experience I would suggest that the optimum dryness value should be 0.97 to 0.98 which allows for sufficient moisture to effect sterilization, without being causal to wet loads.

I would recommend testing the steam quality, including the dryness value, at source of generation, i.e. the PSG. However, during my global travels I have found that this is not the norm, rather it is only tested at 'point of use', e.g. at the autoclave. Whilst point of use is the most obvious position for testing, this is not the full picture. If you test at the PSG and point of use, achieving the same value of, for example 0.97 at each point, then you know the system is 'ideal'. If the values are different at both points, then you already know that something has changed and needs to be investigated. Isn't that much easier than restricting yourself to point of use testing only, and not knowing when something is changing in the system or load until you have to stop manufacturing to investigate the root cause of a fault?

It is therefore recommended to test for steam quality at the PSG, in-line with the flow of steam. It is also recommended to test under static and dynamic conditions to evaluate how reproducible the 
steam quality test results are under varying conditions, including under ' $m$ in and max' demand. If you have never undertaken this test regime before you may be surprised by the results when you try this procedure. It could be a 'light bulb' moment - ah, that's why I have intermittent 'wet' loads! If all is well and you have the desired dryness value you are looking for, you can move on; if not, best to stop at this stage and find the cause of the wet steam. It is also recommended to check for adequate steam trapping at source of generation, to ensure that condensate carryover into the steam service supply line cannot take place which could be causal to wet loads.

\section{The Steam Service:}

From the PSG, the steam supply is delivered to the point of use, i.e. the autoclave. However, there may be several points of use, e.g. more autoclaves, freeze driers, SIP stations. The steam system should have been designed to provide steam to all points of use under maximum demand conditions, in a reproducible manner, and the steam should be of a known and suitable quality throughout. It is important that the system is designed appropriately to ensure that this happens. Basically, it is important to design quality in.

Let us consider a situation where two autoclaves are being supplied by a Pure Steam (PS) system. It is best to install a 'Steam Header' on the mezzanine floor above the autoclaves, so that there is a reservoir of steam available to deliver the necessary steam supply of the required quality. If the Steam Header is omitted from the design, this can be one of the prime reasons for an inadequate steam supply.

It is good practice to install steam quality test points on the Steam Header, which allows the steam to be tested in a safe and efficient manner. An example of a Steam Header can be seen in, 'Health Technical Memorandum 01-01 Part C: Steam sterilization'.

The Steam Header should be fitted with appropriate steam traps, e.g. 'Balanced Pressure, Thermostatic (BPT) steam traps fitted with Near to Steam (NTS) elements'. This type of steam trap, with the NTS element, provides a way of removing unnecessary condensate from the steam supply which otherwise could be causal to wet loads.

So, having determined the importance of the quality of the steam, let's continue our story with the autoclave. I hope your still sitting comfortably.

\section{Steam supply into the Autoclave:}

Let's start with just a single autoclave - although it may be worth remembering that the same principles apply for more than one autoclave.

As can be seen from our story to date, we have now supplied steam of a known and suitable quality to the service area of the autoclave. However, we also need to consider the design of the autoclave and associated pipework, as well as how we get the steam into the chamber, since these will all have an impact on whether we achieve a wet or a dry load.

When the steam comes from the Steam Header on the mezzanine floor (in our earlier scenario) it will be supplied at a known pressure, suitable for its intended purpose. It is important to ensure that the steam supply is, 'a constant' and does not fluctuate. If it fluctuates, pressure drops can occur within the chamber, being causal to excess condensation of the steam which can result in wet loads. The steam should once again be trapped in the service area, with a BPT trap fitted with a NTS element.

If all of the above has been well designed and is controlled appropriately, the PS supply will continue to have a dryness value of 0.97 and that is a very 'nice' position to be in. 


\section{The Autoclave:}

Now we need to understand the challenge of the autoclave itself......

Let's consider an autoclave used for component sterilization, utilizing a Porous/Hardware Load cycle. It has a multi-pulsing air removal stage, heating stage, sterilization stage, vacuum drying stage and an air vent to cycle complete stage.

The autoclave chamber is surrounded by a 'jacket' which is fed with steam to provide uniformity of heating. It is important that the design and operation of the jacket is fit for purpose. By that, what I mean is, if the sterilization stage of the cycle is designed to operate at $\mathrm{c} .122^{\circ} \mathrm{C}$ within the chamber, then the jacket temperature should also be at $122^{\circ} \mathrm{C}$. Why? Well, if the temperature of the jacket is set to a lower temperature, excess condensate will be created as the chamber wall will be cooler than the chamber environment. This excess condensate will potentially 'wet out' the load. Not only could this impact sterilization efficacy, but the resultant will characteristically be a wet load. Then typically, to fix the wet load, we employ 'air waves' (air pulsing) during the vacuum drying stage of the cycle. Whilst this may be an effective solution to the wet load, this has two key disadvantages; firstly, there is a risk to sterility from wet steam and secondly, it increases the length of the cycle, therefore using additional energy and reducing production time. All this to fix a problem that was potentially designed in.

I remember some years ago explaining this to a company who had invited me in to assist them with their sterile operations. After watching a presentation of their current (at that point in time) autoclave component cycle, I asked if they would like to understand how their cycle could be reduced from 4.5 to 1.5/2 hours... The Production Director was first to his feet, "Alan, how can we do this, please....."

Whilst we are still thinking about the autoclave jacket, let's consider another potential design problem. Many years ago, dedicated Porous Load autoclaves in the UK were designed with autoclave jackets which had their temperature set the same as the sterilization stage temperature of the cycle. The 'steam to jacket' was always on, which meant that the autoclave chamber was always hot and at a constant temperature. The doors were also hot when in the closed position. When a new load was placed within the chamber, the only cold items were the load itself and the autoclave rack, therefore the condensate that was created from the steam entering the chamber was created by its contact with the load and rack, not by the inside chamber wall and cold doors. However, today, it is more typical in industry to find the opposite as the norm, whereby steam is turned off to the jacket, either during the drying vacuum stage or at the end of the cycle; consequently, the autoclave becomes 'cold' at rest. Then, at some point, when a new load is placed into the autoclave chamber, if the jacket and doors are cooler than the steam entering the chamber, then of course condensate will be created. This is not what we want, since this condensate will lead to the 'wetting out' of the load. Therefore too much condensate will be created at the beginning of the cycle and the drying vacuum stage of the cycle will be ineffective; the result being a wet load. So, in effect, the wet load is once again 'designed in'. This is a major challenge in our industry and should be a cause for concern.

In our example autoclave, PS is supplied to both the chamber and the jacket; however, not all autoclaves operate in this manner. Sometimes, 'Plant Steam' is supplied to the jacket and PS only to the chamber; typically due to a supposed commercial rationale to save money - something which in my experience can lead to more production/product problems and consequently the financial savings may only have been short term, at best. But I digress. No soap boxes in this story... keep to the facts and data Alan. Factually, the use of plant steam can have a negative impact on the uniformity of temperature within the jacket if 'scaling up' occurs within the jacket (think of scale build up in your kitchen kettle). One way to determine if this is happening is to perform a 'Jacket 
Mapping' study, whereby thermocouples (TC's) are attached in varying locations, in intimate contact to the chamber wall and a cycle is performed. If lower temperatures than expected are measured, this indicates that non-uniformity of temperature exists which can/will result in a wet load.

You may now be thinking, "Alan, this is more complex than I thought...!" Well, not really, hang-in there; this will ultimately make life much easier and more enjoyable if you can deal with those intermittent (or more than intermittent!) wet loads. So next, let's go on to the autoclave and cycle design, as well as the actual operation of the autoclave.

\section{The Autoclave and Cycle Design:}

I'm sure you can see from the story so far that the way the autoclave is designed can have a major impact on whether loads are wet or dry on completion of a cycle. However, the design of the cycle itself and the operation of the autoclave can also impact on the load wet/dry condition. Let's consider a couple of scenarios in a bit more detail - nothing like, 'real situations' to understand better.

Firstly, let's assume that the steam being supplied to the jacket is not on at all times and in fact, during the final stages of the cycle, the steam is removed from the jacket and a cooling stage is employed in the chamber. On completion of the cycle the load is removed from the chamber and a new load is subsequently placed inside the chamber. We now have a situation where the chamber, jacket, doors and load are 'cold'. Then, when the doors are closed and locked, the next cycle is initiated. At this point, dependent on the type of autoclave and its design, typically steam is admitted to the jacket. Remember that earlier I suggested that the jacket temperature should be the same as the sterilizing stage temperature; let's say in this scenario at c. $122.5^{\circ} \mathrm{C}$. However, in this example, when the temperature in the jacket reaches its 'designed in' set point, e.g. $117^{\circ} \mathrm{C}$, the cycle starts. Now clearly $117^{\circ} \mathrm{C}$ is much lower than $122.5^{\circ} \mathrm{C}$; however, if the sensor detecting the set point of $117^{\circ} \mathrm{C}$ is positioned at a high level point within the jacket, it would be fair to suggest that in the lower sections of the jacket the temperatures will be lower; so not even reaching $117^{\circ} \mathrm{C}$. Therefore, when steam enters the chamber during its first pulse, it condenses out on the relatively cold chamber wall, doors, autoclave rack and load. If too much condensate is created during the initial stage of the cycle it will not be removed during the drying vacuum stage of the cycle.

I often use the following example when trying to explain this point: "Imagine that I am going to take my jacket off and soak it with water. I then put my wet jacket (coat for the American reader $(-)$ ) in the autoclave chamber and run a cycle. On completion of the cycle will the jacket be wet or dry?" In case you are wondering; the jacket will be wet. Why? Because there was too much water entrained in the material for the vacuum drying stage of the cycle to remove it. So, you clearly point out to me, "Alan, we are not going to put wet clothing into the autoclave"; however, whatever the load is, if it's wetted out during the initial stages of the cycle, the effect will be the same - a wet load will result.

Secondly, let's assume that we are not going to put a wet jacket into the autoclave, but rather a wrapped mixed component load. The autoclave and cycle design is exactly the same as for the previous scenario; however this time the load comprises of tubing, filters and stainless steel items (one of those complex, tricky loads - but Alan, we have to do this load - and so, all hands on deck to qualify the load and get into production!).

Following the sterilization stage of the cycle, a vacuum is pulled in the chamber to 'dry off' the load. The principle involved here is that the heat energy transferred to the load during the cycle is now utilized to 'flash off' the condensate during vacuum conditions being applied in the chamber. However, for this to happen it is wholly dependent on the load item itself, the rate of 
vacuum pull down and the level of vacuum attained, and the time it is held at that level. It should be understood that the amount of heat energy retained in stainless steel for example, will be different than silicone tubing, filters etc. Therefore, it is possible that some components will be dry and others could be wet, depending on the autoclave and cycle design. But don't forget in this example steam is exhausted from the chamber jacket during the vacuum drying stage. Of course, if we design the autoclave system in such a way that steam to the jacket is on all the time, then the likelihood of achieving a dry load is greatly increased.

I hope you are still enjoying the story - then I'll continue; on to the load design, prep and configuration.

\section{Load Design, Preparation and Configuration:}

As we have seen so far, the design and operation of our steam supply, as well as the design of the autoclave and cycle, all have a part to play in relation to the wet/dry condition of our load. Now we come to the load itself.

Let's consider the same component load discussed in the second scenario above (the challenging mixed load, loved by all....). Depending how well the load items are designed, prepped and configured on the autoclave rack, will in part dictate whether the items come out of the autoclave wet or dry at the end of a cycle. What are the challenges involved?

Well, let's consider using a simple example of a cup - if the cup is placed upright it will fill up with water. OK, no problem, we'll turn it upside down - that should do it; aha, there is a lip on the bottom of the cup, so that will collect water. Um.... OK, let's turn the cup upside down and angle it so that water won't collect on the underside of the cup; it will self-drain. Yes! Now if you use that simple model you can organize the load to limit condensate collection and reduce the risk of a wet load; not always, but mostly. There are always limitations and difficulties to face if we want to sterilize complex, mixed loads - especially if we are wanting to reduce the overall number of loads. However, if we approach our load design in the right, 'logical' way, each item at a time, we have the possibility of achieving a dry load. Who doesn't love a challenge - and it may even be fun (can we use that word?).

Now, let's take the same component load as discussed earlier, but this time let's 'double bag' each of the components, such that each item now has two layers of packaging. Depending on the type of packaging employed and how well it is wrapped will have an impact on whether our load is wet or dry. Why is this? Well, let's go back a few years, well, maybe quite a few years, when many components were wrapped in paper autoclavable bags. Then the industry moved to paper/film bags; then to Tyvek. So, what was the effect of this change in packaging materials? Well, let me give you an example:

If I took a stainless steel component and placed it in a paper bag and then sealed it, would it come out of the autoclave dry on completion of a cycle? Typically, yes. However, if I took the same component and positioned it in a paper/film bag would it be dry? Mostly.

If I took the same component and positioned it in a Tyvek bag, would it be dry? Possibly, but maybe not.

To illustrate this a little further, hopefully without labouring the point overly, but wanting you the reader to realise the impact, let's consider a load with no packaging material. If we have a welldesigned 'system', and our load has been configured appropriately, then the load will be dry on completion of cycle. If we now put each load item into some form of packaging material and then autoclave it, and it comes out wet, shouldn't we start looking at the packaging material and the technique of how each item is prepared?

Why not try this out for yourself, comparing an unpackaged load with your usual packaged wet load, just to verify this and help focus your efforts? 
So, what is happening to our load with our selected packaging choice? Well, we know that in order to sterilize a component load type we need to remove air from all parts of the load and replace it with steam of a suitable quality. We then hold the load at a suitable temperature for a suitable length of time to effect sterilization. But now the load is wet. So, we pull a deep vacuum following the sterilization stage and use the latent heat energy imparted to the load through the sterilization process to dry off the load. I 'grew up' in the health care industry knowing that I could get a dry load if I pulled a drying stage vacuum down to $50 \mathrm{mb}$ and held that vacuum for 5 minutes; if it was complex, 10 minutes. Really? Yes, really. Why then on my travels do I see drying vacuum stages of 30 minutes to 2 hours plus, with multiple 'air wave' pulses being employed? This makes the overall cycle time long and inefficient.

OK, let's back-up. No packaging - dry load. Double bagged load item - wet load; why? When steam hits the outside of the load packaging it condenses and imparts its heat energy. More steam fills the gap and on it goes until we get to the start of the sterilization phase, etc., etc. But at the end of the cycle we open the packaging and find water in the bag and component - why? Let's assume for this example that the component is made of stainless steel. When the steam goes through the packaging and hits the component, it condenses and imparts its heat energy to the load item. Where does the condensate go? Into the bag. However, dependent on the material of the bag, e.g. if it is water repellent and it won't go through the bag; it sits there. The only way that we can now dry the load efficiently is if that condensate is held in intimate contact with the load item, so that during the drying vacuum process the latent heat energy within the load item enables the moisture to 'flash-off' under vacuum conditions during the drying phase of the cycle. If the moisture migrates from the load item and sits in the bag it will still be there when the cycle has completed. I hope this helps you to understand what is happening in your loads and what needs to be taken into consideration when configuring a 'good' load. Specifically, remember to consider not only the material of construction, but the way it is assembled and configured, as well as the packaging of choice and the potential disadvantages of 'over bagging' in relation to air removal, steam penetration and the resultant wet or dry load.

\section{Concluding thoughts:}

So, how do we get a dry load? Simply put, by ensuring that we take into account everything we have discussed in our story, i.e. the steam quality, the system design including the autoclave and the cycle, as well as the packaging, preparation and configuration of the load to enable efficacy of sterilization and the possibility of achieving a dry load.

Of course you could just try and employ multiple air waves during the drying phase of the cycle in an attempt to dry the load; however, that can be a very timely process. It should be possible to complete a $121^{\circ} \mathrm{C}$ component load cycle within 1.5 hours. How long are your autoclave cycles? How much energy and production time are you wasting? Are you wasting so much time that you actually need another autoclave to achieve your desired production capacity?

I always like a happy ending - otherwise, how is it a good story? Isn't it good to know that it is possible to autoclave load components, finding them to be dry on completion of a cycle, ensuring appropriate sterility assurance in a reproducible way, if we consider all of the above aspects. Hence the title to this story, 'Wet loads - a phenomenon or by design?' It has long been my concern that the wet load phenomenon is in fact caused by design, so hopefully, this story will in part, help redress that. 
Maybe it would be help even more if this story was just the beginning of a move to bring together those involved in the design and installation of PS generation and distribution systems, autoclave design and functionality, load equipment, and sterile barrier packaging for the specific purpose of steam sterilization; all of this with the main objective of being able to produce dry sterile products in the most efficient way possible, and on a reproducible basis. Now, wouldn't that be a good idea?

Thank you for reading this story - I hope you have found it interesting and helpful. Maybe it's time we went on an adventure..... 